\title{
Stool preparation under anaerobic conditions contributes to retention of obligate anaerobes: potential improvement for fecal microbiota transplantation
}

\author{
Hirotaka Shimizu ${ }^{1,2^{*}}$, Katsuhiro Arai ${ }^{1}$, Takashi Asahara ${ }^{3,4}$, Takuya Takahashi ${ }^{3,4}$, Hirokazu Tsuji $i^{3,4}$, \\ Satoshi Matsumoto ${ }^{3,4}$, Ichiro Takeuchi ${ }^{1,2}$, Reiko Kyodo ${ }^{1,2}$ and Yuichiro Yamashiro ${ }^{4}$
}

\begin{abstract}
Background: Fecal microbiota transplantation (FMT) in patients with ulcerative colitis has shown variable efficacy depending on the protocol used. A previous randomized controlled trial reported that anaerobic preparation of donor stool contributes to improved efficacy. Despite the suggestion that viable obligate anaerobes would be decreased through aerobic handling, there have been only a limited number of reports on how these aerobic or anaerobic procedures affect the composition of viable microbiota in the fecal slurries used for FMT.
\end{abstract}

Methods: We adopted $16 \mathrm{~S}$ and $23 \mathrm{~S}$ rRNA-targeted reverse transcription-quantitative polymerase chain reaction to quantify viable bacteria in fecal slurries. This study utilized specific primers designed to detect obligate anaerobes (including Clostridium coccoides group, C. leptum subgroup, Bacteroides fragilis group, Bifidobacterium, Atopobium cluster, and Prevotella) and facultative anaerobes (including total lactobacilli, Enterobacteriaceae, Enterococcus, Streptococcus, and Staphylococcus). We then calculated the ratio change (RC) between before and after mixing, and compared the resulting values between anaerobic-prep and aerobic-prep in samples fixed immediately after blending $\left(\mathrm{RC}_{\text {Ano }} \mathrm{VS}\right.$. $R C_{A e 0}$ ) and in samples maintained (under anaerobic or aerobic conditions) for $1 \mathrm{~h}$ after blending $\left(\mathrm{RC}_{\mathrm{An} 1} \mathrm{VS} . \mathrm{RC} \mathrm{Ce}_{\mathrm{Ae}}\right)$.

Results: For most obligate anaerobes, the median RC tended to be less than 1, indicating that the number of obligate anaerobes was decreased by the blending procedure. However, in samples maintained for $1 \mathrm{~h}$ after blending, anaerobic-prep counteracted the decrease otherwise seen for the C. coccoides group and $B$. fragilis groups $(P<0.01$ for both). The C. leptum subgroup also tended to show higher RC by anaerobic-prep than by aerobic-prep, although this effect was not statistically significant. Among facultative anaerobes, Enterobacteriaceae, Enterococcus, and Staphylococcus showed median RC values of more than 1, indicating that these organisms survived and even grew after mixing. Moreover, oxygen exposure had no significant influence on the survival of the facultative anaerobes.

Conclusions: The conditions under which the blending procedure was performed affected the proportion of live anaerobes in fecal slurries. The obligate anaerobes tended to be decreased by blending processes, but anaerobicprep significantly mitigated this effect. Anaerobic-prep may improve the efficacy of FMT by permitting the efficient transfer of obligate anaerobes to patients with ulcerative colitis.

\footnotetext{
*Correspondence: shimizu-h@ncchd.go.jp

${ }^{1}$ Division of Gastroenterology, Department of Medical Specialty, National

Center for Child Health and Development, Tokyo, Japan

Full list of author information is available at the end of the article
} original author(s) and the source, provide a link to the Creative Commons licence, and indicate if changes were made. The images or other third party material in this article are included in the article's Creative Commons licence, unless indicated otherwise in a credit line to the material. If material is not included in the article's Creative Commons licence and your intended use is not permitted by statutory regulation or exceeds the permitted use, you will need to obtain permission directly from the copyright holder. To view a copy of this licence, visit http://creativecommons.org/licenses/by/4.0/. The Creative Commons Public Domain Dedication waiver (http://creativeco mmons.org/publicdomain/zero/1.0/) applies to the data made available in this article, unless otherwise stated in a credit line to the data. 
Keywords: Obligate anaerobes, Fecal microbiota transplantation, Anaerobic preparation

\section{Background}

The advent of high-throughput DNA-based sequencing technology to classify bacteria according to $16 \mathrm{~S}$ rRNA sequences has enabled identification of obligate anaerobes, a class that was difficult to capture by traditional culture techniques [1]. As a result, it was revealed that the obligate anaerobes comprise most of the healthy intestinal microbiota and have beneficial effects on our health [2]. For example, some obligate anaerobes (such as Clostridium cluster IV and XIVa) ferment dietary fibers and produce short-chain fatty acids, such as acetic acid and butyric acid [3]. Acetic acid has an antimicrobial effect on pathogenic bacteria [4], and butyric acid serves as a significant nutritional source for colonic epithelia and induces the differentiation of regulatory $T$ cells [5].

Disruption of the bacterial balance is defined as dysbiosis. Recently, dysbiosis has been reported to be associated with the pathogenesis of various disorders, including inflammatory bowel disease, allergy, metabolic syndrome, and obesity. Indeed, in patients with ulcerative colitis (UC), a decrease in the abundance of obligate anaerobes (such as Bacteroidetes and Firmicutes) and an increase in abundance of facultative anaerobes (such as Enterobacteriaceae and Enterococcaceae) has been reported [6-8].

In 2013, Nood et al. reported the effect of fecal microbiota transplantation (FMT) for recurrent Clostridioides (formerly Clostridium) difficile infection (CDI), with an impressive cure rate of more than 90\% [9]. Since then, FMT has become established as a therapy for recurrent $\mathrm{CDI}$, and there is growing evidence for the utility of FMT against UC. In recent years, randomized controlled trials studying the application of FMT in patients with UC have reported varying results [10-13]. Unfortunately, the efficacy of FMT for the treatment of UC appears to be less than that of FMT for the treatment of CDI. Considering the decreases observed in beneficial obligate anaerobes in UC patients, delivery of these beneficial bacteria-rich fecal slurries might be the key to improving the efficacy of FMT for patients with UC.

However, in most studies, FMT suspensions were diluted with normal saline and homogenized using a blender in room air. Such oxygen exposure could cause the death of these beneficial bacteria because most are obligate anaerobes [14]. As a result, the number of live beneficial obligate anaerobes in fecal slurries may be decreased through the aerobic blending procedure. This compositional change of microbiota may be associated with the lower efficacy of FMT in patients with UC.
If anaerobic preparation, which reduces oxygen exposure, facilitates the retention of viable obligate anaerobes, outcomes of FMT might be improved. Indeed, Costello et al. observed the effectiveness of anaerobic preparation of donor stool in a randomized controlled trial of FMT for UC patients [13]. Moreover, Ding et al. reported a remarkably high response rate of step-up FMT strategy (clinical response rate at 1 month was as high as $74 \%$ ), which utilizes an automatic system that can process fresh donor stool within $1 \mathrm{~h}$ of defecation [15]. These anaerobic or rapid preparation methods seem to reduce oxygen exposure and result in the survival of beneficial obligate anaerobes.

However, it has been difficult to determine how much the blending procedure impacts bacterial viability. Papanicolas et al. combined propidium monoazide (PMA) treatment with $16 \mathrm{~S}$ rRNA gene amplicon sequencing to quantitatively assess the effect of the blending procedure on the abundance of viable bacteria in fecal slurries [16]. Those authors processed samples with PMA within $15 \mathrm{~min}$ of blending and reported that aerobic blending resulted in significantly lower bacterial viability (19\%) than did anaerobic blending (50\%). Papanicolas et al. further showed that butyrate and acetate production was decreased in aerobically prepared samples compared to production in anaerobically processed samples. These findings illustrated the importance of anaerobic stool processing.

In the present study, we collected 1-h samples that were stabilized by RNAlater after 1 -h maintenance under the anaerobic or aerobic conditions, in addition to 0 - $h$ samples that were stabilized immediately after blending (Fig. 1). We considered that the 1-h samples reflected the actual clinical settings in which FMT typically would be performed. Because the administration of FMT solution by endoscope or enema tube usually takes time, the timely insertion of FMT solution within $15 \mathrm{~min}$ seems to be difficult.

To evaluate bacterial viability, we adopted the Yakult Intestinal Flora-SCAN (YIF-SCAN ${ }^{\circledR}$ ) system. This system utilizes reverse transcription-quantitative polymerase chain reaction (RT-qPCR) to target bacterial rRNA. Since rRNA in dead cells is rapidly degraded, this method permits quantitative determination of the number of viable cells. Moreover, the sensitivity of this system is theoretically 100-1000 fold higher than that of qPCR assays that target rRNA genes (which exist at 5-10 copies per bacterial cell), as the rRNA molecules exist abundantly (approximately $10^{4}$ copies per bacterial cell) [14, 


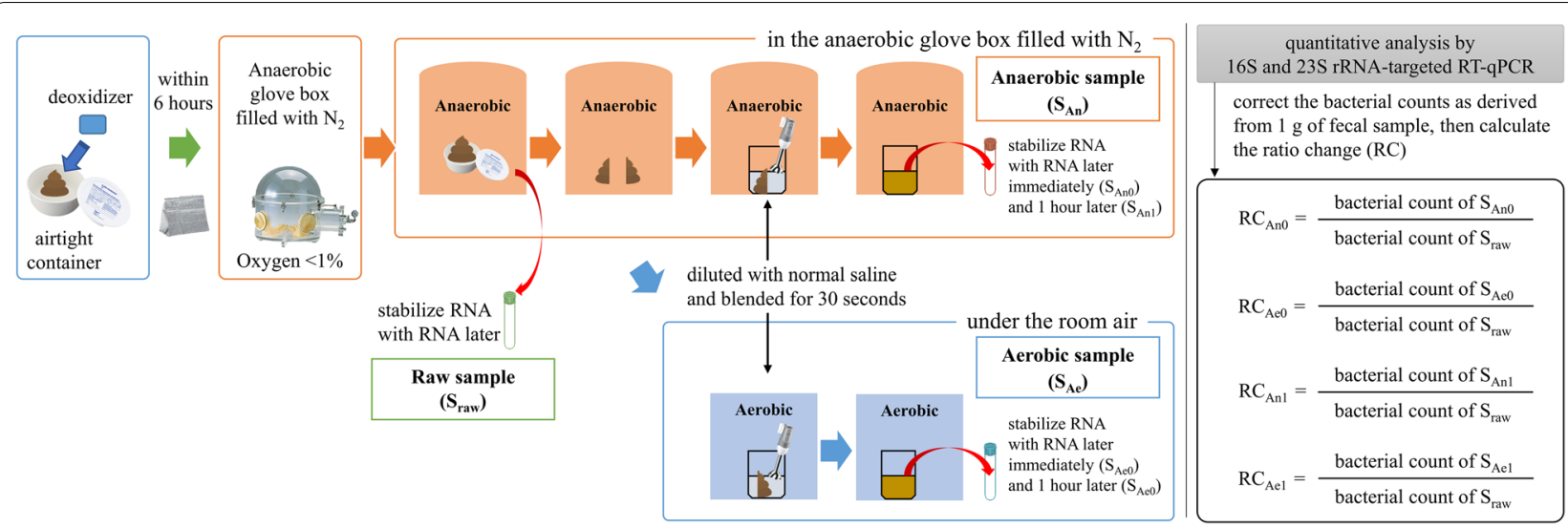

Fig. 1 Stool collection and anaerobic and aerobic preparation. Fecal samples from 16 healthy adults were transferred under anaerobic conditions using an airtight container and deoxidizer and aliquoted into two portions in an anaerobic glove box. Each aliquot then was diluted with normal saline and blended for 30 s, either in the anaerobic glove box (anaerobic-prep) or under room air (aerobic-prep). Fecal samples were collected before blending $\left(\mathrm{S}_{\text {raw }}\right)$, and then immediately $(0 \mathrm{~h})$ and $1 \mathrm{~h}$ after anaerobic-prep $\left(\mathrm{S}_{\mathrm{An} 0}\right.$ and $\mathrm{S}_{\mathrm{An} 1}$, respectively), or at 0 and $1 \mathrm{~h}$ after aerobic-prep $\left(\mathrm{S}_{\text {Ae0 }}\right.$ and $S_{\mathrm{Ae} 1}$, respectively)

17]. Therefore, RT-qPCR is a more sensitive assay and is expected to detect rRNA only from live bacteria in the specimens [17].

Using this technique, we sought to examine the effectiveness of anaerobic preparation in preserving viable obligate anaerobes in real-world clinical settings.

\section{Results}

\section{Fecal bacterial composition in samples before blending} $\left(S_{\text {raw }}\right)$

The bacterial composition of raw samples (before blending of samples) from the 16 subjects is shown in Supplementary Table 1 (where data are shown in logarithmic form). The stacked bar chart is shown in Fig. 2 (where data are shown in real numbers).

The proportion of the facultative anaerobes was significantly lower than that of the obligate anaerobes. In most samples (except for subjects 6 and 7), the Clostridium coccoides group (corresponding to Clostridium cluster $\mathrm{XIVa}$ ) and the C. leptum subgroup (corresponding to Clostridium cluster IV) accounted for the majority of the fecal microbiota. Subject 6 was rich in the Bifidobacterium and Bacteroides fragilis groups, and subject 7 was abundant in the Atopobium cluster.

\section{Comparison of the ratio change in viable bacteria before and after preparation}

In the present study, we calculated the ratio change (RC) in the number of viable bacteria before and after the preparation. For the bacterial groups whose numbers were below the detection limit, the value was set to $50 \%$ of each lower limit. The RC was then calculated by dividing the number of bacteria after mixing $\left(\mathrm{S}_{\mathrm{An} 0}, \mathrm{~S}_{\mathrm{An} 1}\right.$,
$\mathrm{S}_{\mathrm{Ae} 0}$, or $\left.\mathrm{S}_{\mathrm{Ae} 1}\right)$ by the original number of bacteria $\left(\mathrm{S}_{\mathrm{raw}}\right)$. The formula for the RC is shown in Fig. 1. We then compared bacterial viability between anaerobic-prep and aerobic-prep.

Fig. 3 shows the comparison of RCs in the number of live bacteria for A: total bacteria, B: total obligate anaerobes, $\mathbf{C}-\mathbf{H}$ : each of the obligate anaerobes, $\mathbf{I}$ : total facultative anaerobes, and $\mathbf{J}-\mathbf{N}$ : each of the facultative anaerobes. Each box plot compared the RCs of anaerobicprep and aerobic-prep in samples stabilized immediately after blending $\left(\mathrm{RC}_{\mathrm{An} 0}\right.$ and $\left.\mathrm{RC}_{\mathrm{Ae} 0}\right)$, and also in samples stabilized following $1 \mathrm{~h}$ of maintenance under the respective anaerobic or aerobic conditions $\left(\mathrm{RC}_{\mathrm{An} 1}\right.$ and $\left.\mathrm{RC}_{\mathrm{Ae} 1}\right)$.

In samples stabilized immediately after blending (0-h samples; $\mathrm{RC}_{\mathrm{An0}}$ and $\mathrm{RC}_{\mathrm{Ae} 0}$ ), the median $\mathrm{RC}$ values of the obligate anaerobes were less than 1 (Figs. $3 \mathrm{~A}-\mathrm{H}$ ). The RC of anaerobic-prep $\left(\mathrm{RC}_{\mathrm{An} 0}\right)$ tended to be higher than that of the aerobic-prep $\left(\mathrm{RC}_{\mathrm{Ae} 0}\right)$, although the differences did not reach statistical significance.

For samples stabilized at $1 \mathrm{~h}$ after blending (1-h samples), the $\mathrm{RC}_{\mathrm{An} 1}$ was significantly higher than the $\mathrm{RC}_{\mathrm{Ae} 1}$ for the C. coccoides group (Fig. $3 \mathrm{C}$ ) and B. fragilis group (Fig. 3E) $(P<0.001$ and $P<0.01$, respectively). Additionally, the $\mathrm{RC}_{\mathrm{An} 1}$ for the $C$. leptum subgroup tended to be higher than the $\mathrm{RC}_{\mathrm{Ael}}$ (Fig. 3D), although this difference was not statistically significant. There were no significant differences between the $\mathrm{RC}_{\mathrm{An} 1}$ and $\mathrm{RC}_{\mathrm{Ae} 1}$ values for the other obligate anaerobes (Bifidobacterium cluster, Atopobium cluster, and Prevotella).

For facultative anaerobes, the median $\mathrm{RC}$ values for the Enterobacteriaceae (Fig. 3K), the Enterococcus (Fig. 3L), and the Staphylococcus (Fig. 3N) tended to be more than 1 , indicating that these organisms survived and even 


\begin{tabular}{|c|c|c|c|}
\hline Clostridium coccoides group & Clostridium leptum subgroup & Bacteroides fragilis group & Bifidobacterium \\
\hline Atopobium cluster & Prevotella & Clostridioides difficile & - Clostridium perfringens \\
\hline Total lactobacilli & Enterobacteriaceae & Enterococcus & Streptococcus \\
\hline - Staphylococcus & & & \\
\hline
\end{tabular}

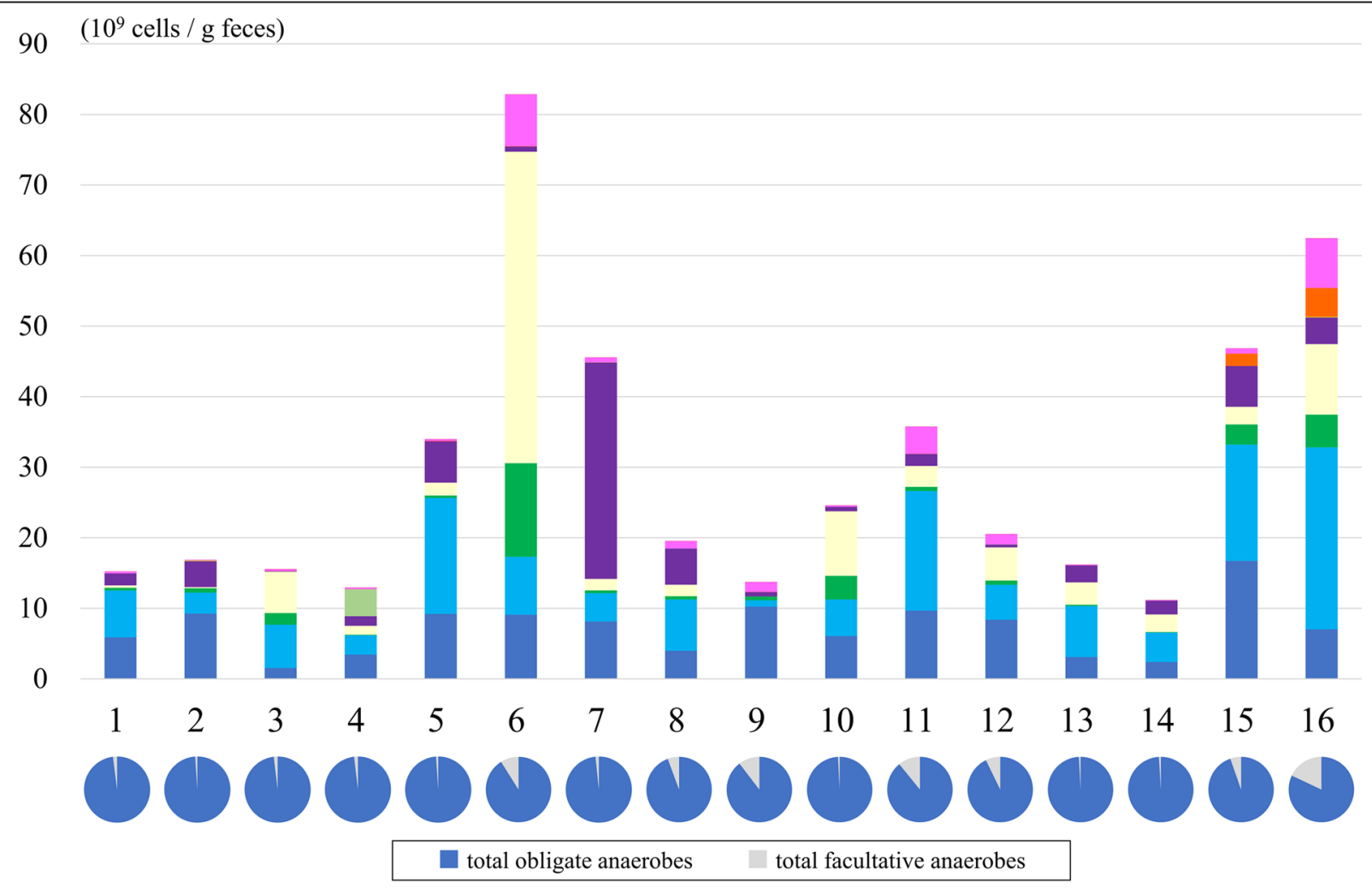

Fig. 2 The bacterial composition of raw samples from 16 subjects. Each stacked bar represents bacterial counts per $1 \mathrm{~g}$ of feces, as determined by $16 \mathrm{~S}$ and $23 \mathrm{~S}$ quantitative reverse transcription-polymerase chain reaction (RT-qPCR). In all subjects (except subjects 6 and 7), obligate anaerobes, including the C. coccoides group and C. leptum subgroup, accounted for the majority of the fecal microbiota. The proportion of the facultative anaerobes was significantly lower than that of the obligate anaerobes

grew after the mixing procedure. For Enterobacteriaceae, Enterococcus, Streptococcus, and Staphylococcus, there was no significant difference between $\mathrm{RC}_{\mathrm{An} 1}$ and $\mathrm{RC}_{\mathrm{Ae} 1}$. These results indicated that oxygen exposure had no significant influence on the survival of facultative anaerobes.

\section{Discussion}

This study compared the number of live bacteria in fecal slurries for FMT between anaerobic-prep and aerobicprep using RT-qPCR targeting bacterial rRNA. Notably, a larger number of viable obligate anaerobes were retained in slurries processed by anaerobic-prep.

In a previous randomized controlled trial, Costello et al. [13] assessed changes in fecal microbiota by $16 \mathrm{~S}$ rRNA gene sequencing. Those authors reported that increases in the abundances of Anaerofilum pentosovorans, Bacteroides coprophilus, and Clostridium methylpentosum after FMT were strongly associated with the improvement of UC. Costello et al. also noted that organisms whose abundances were positively related to improved outcomes were primarily obligate anaerobes. In the present study, we conducted RT-qPCR targeting bacterial rRNA to quantify live bacteria. In this taxonomy, the C. coccoides group (Clostridium cluster XIVa) consists of the genera Ruminococcus, Eubacteria, Coprococcus, and Lachnospira. Likewise, the C. leptum subgroup (Clostridium cluster IV) contains the genera Anaerofilum, Faecalibacterium, and Ruminococcus, and the $B$. fragilis group includes the major Bacteroides species. Notably, most bacteria associated with treatment response in the above RCT belonged to one of these three groups. In this regard, it is significant that anaerobic-prep was related to retention of these three groups of bacteria.

In the current work, the abundance of facultative anaerobes, such as Enterobacteriaceae and Enterococcus, tended to increase after processing. The increased 


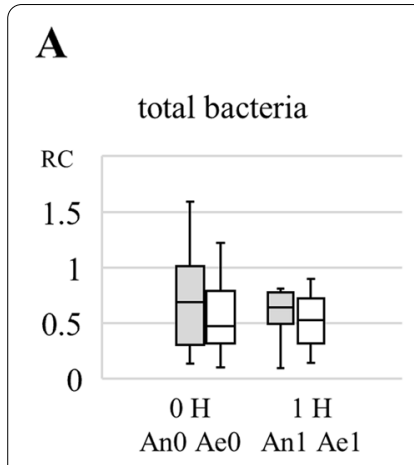

$\mathbf{E}$

\section{B. fragilis group}

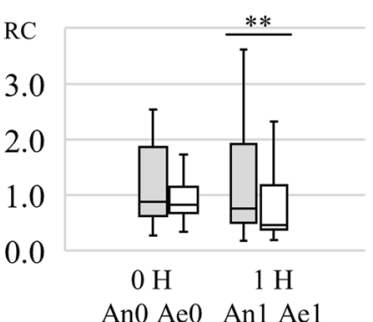

I

total facultative anaerobes

$\mathrm{RC}$

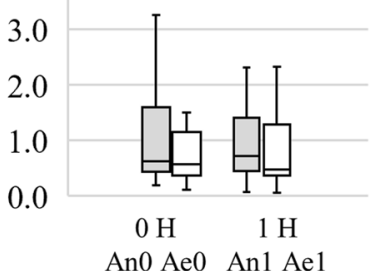

M

Streptococcus

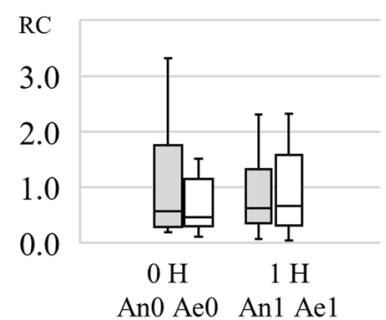

B

total obligate anaerobes

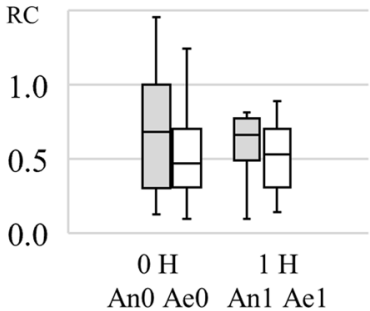

F

Bifidobacterium

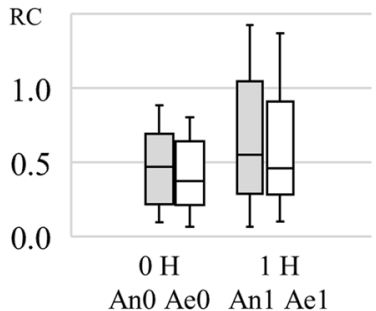

J

total Lactobacilli

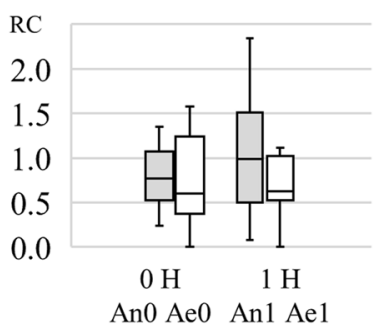

$\mathbf{N}$

Staphylococcus

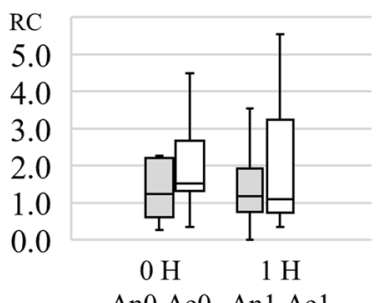

C

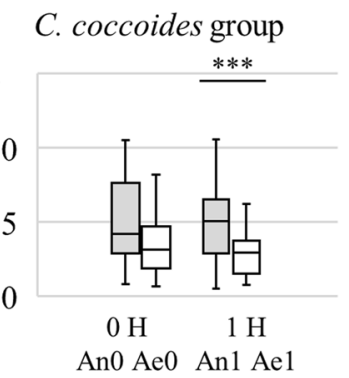

G

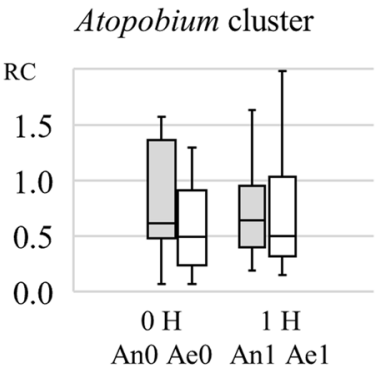

K

Enterobacteriaceae

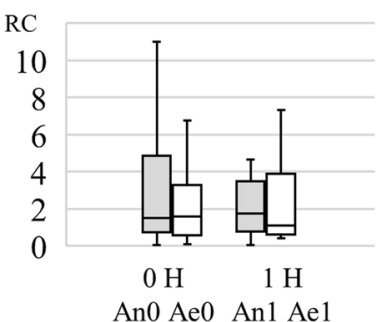

D

C. leptum subgroup

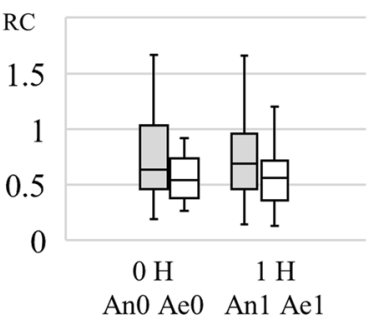

H

Prevotella

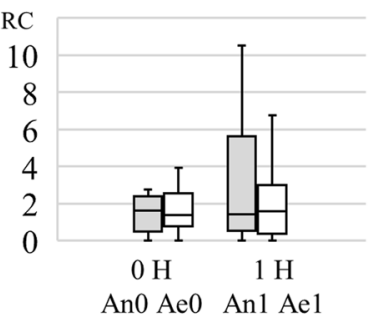

$\mathbf{L}$

Enterococcus

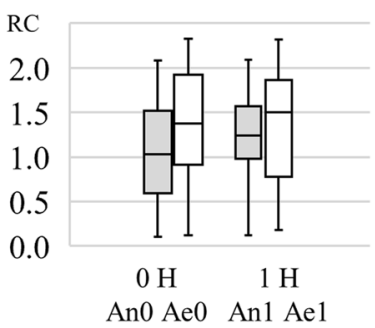

Fig. 3 Comparison of the ratio change in the obligate and facultative anaerobes. These charts show the comparison of the ratio change (RC) in the number of live bacteria for $\mathbf{A}$ : total bacteria, B: total obligate anaerobes, $\mathbf{C}-\mathbf{H}$ : each of the obligate anaerobes, I: total facultative anaerobes, and J-N: each of the facultative anaerobes. An RC value of more than 1 indicates that the bacterial group survived and even grew after the blending procedure. The box plot depicts the median and interquartile range and error bars represent the minimum and maximum values of the RC from 16 healthy volunteers. Each box plot compared RCs of anaerobic-prep and aerobic-prep, for samples stabilized immediately after blending (RC $\mathrm{Ano}$ and $\left.R C_{A e 0}\right)$, and also for samples stabilized after maintenance for $1 \mathrm{~h}$ under the respective anaerobic or aerobic conditions $\left(\mathrm{RC}_{\mathrm{An} 1}\right.$ and $\left.R C_{\mathrm{Ae} 1}\right)$. Significant differences are indicated by asterisks $\left({ }^{* *} P<0.01,{ }^{* *} P<0.001\right.$; Wilcoxon signed-rank sum test) 
abundance of these facultative anaerobes is not favorable because these anaerobes have been reported to increase in active-phase UC patients. However, the absolute number of facultative anaerobes remained markedly lower than that of the obligate anaerobes (Table 1). Conversely, for obligate anaerobes, the RCs obtained by anaerobicprep and aerobic-prep differed by 0.3 or less. However, these RC differences would significantly impact the absolute number of obligate anaerobes, given that these organisms are present at billions per gram of feces at baseline.

As mentioned previously, Papanicolas et al. reported that anaerobic-prep was associated with improved viability of anaerobes, but noted that only $50 \%$ of the bacterial content was viable even with anaerobic-prep. Those data were obtained based on samples treated with PMA within $15 \mathrm{~min}$ of blending. Our results, obtained from samples treated immediately after blending $\left(\mathrm{RC}_{\mathrm{An} 0}\right)$, are consistent with those of Papanicolas et al. We also showed that samples maintained for $1 \mathrm{~h}$ under anaerobic conditions $\left(\mathrm{RC}_{\mathrm{An} 1}\right)$ exhibited viabilities essentially identical to those collected and stabilized immediately after processing $\left(\mathrm{RC}_{\mathrm{An} 0}\right)$. We believe that the sampling in our study better reflects the real-world setting, given that the fecal slurries employed for FMT seldom are transplanted to patients within $15 \mathrm{~min}$ of collection. Indeed, the interval from blending to administration would typically exceed $15 \mathrm{~min}$, considering

Table 1 Fecal counts of gut microbiota as determined by RT-qPCR

\begin{tabular}{|c|c|c|c|c|c|c|}
\hline & \multicolumn{2}{|l|}{$\mathrm{OH}$ samples } & \multirow[b]{2}{*}{$P$} & \multicolumn{2}{|l|}{$1 \mathrm{H}$ samples } & \multirow[b]{2}{*}{$P$} \\
\hline & $\begin{array}{l}\text { Anaerobic samples } \\
(n=16)\end{array}$ & $\begin{array}{l}\text { Aerobic samples } \\
(n=16)\end{array}$ & & $\begin{array}{l}\text { Anaerobic samples } \\
(n=16)\end{array}$ & $\begin{array}{l}\text { Aerobic samples } \\
(n=16)\end{array}$ & \\
\hline Total bacterial counts & $10.1 \pm 0.3$ & $10.0 \pm 0.3$ & & $10.2 \pm 0.3$ & $10.1 \pm 0.3$ & \\
\hline \multicolumn{7}{|l|}{ Obligate anaerobe } \\
\hline Clostridium coccoides group & $9.4 \pm 0.4$ & $9.2 \pm 0.4$ & & $9.4 \pm 0.4$ & $9.2 \pm 0.4$ & $* * 0.0042$ \\
\hline C.leptum subgroup & $9.6 \pm 0.4$ & $9.5 \pm 0.4$ & & $9.6 \pm 0.4$ & $9.5 \pm 0.4$ & ${ }^{* *} 0.1750$ \\
\hline Bacteroides fragilis group & $8.8 \pm 0.6$ & $8.8 \pm 0.6$ & & $8.8 \pm 0.6$ & $8.6 \pm 0.6$ & \\
\hline Bifidobacterium & $8.9 \pm 0.7$ & $8.8 \pm 0.8$ & & $9.0 \pm 0.7$ & $8.9 \pm 0.7$ & \\
\hline Atopobium cluster & $9.1 \pm 0.5$ & $9.0 \pm 0.4$ & & $9.1 \pm 0.5$ & $9.0 \pm 0.5$ & \\
\hline Prevotella & $5.9 \pm 1.9$ & $6.1 \pm 1.4$ & & $5.9 \pm 1.9$ & $5.6 \pm 2.0$ & \\
\hline C.difficile & $1.2 \pm 0.0$ & $1.3 \pm 0.4$ & & $1.4 \pm 0.9$ & $1.2 \pm 0.0$ & \\
\hline C.Perfringens & $1.5 \pm 1.0$ & $1.4 \pm 0.8$ & & $1.2 \pm 0.0$ & $1.8 \pm 1.3$ & \\
\hline \multicolumn{7}{|l|}{ Faculative anaerobe } \\
\hline Total lactobacilli & $5.8 \pm 1.0$ & $5.7 \pm 1.4$ & & $6.0 \pm 1.2$ & $5.6 \pm 1.5$ & \\
\hline Lactobacillus (formerly L. gasseri subgroup) & $4.2 \pm 2.1$ & $4.3 \pm 2.0$ & & $4.4 \pm 2.2$ & $4.2 \pm 2.1$ & \\
\hline Levilactobacillus brevis (formerly L. brevis) & $1.8 \pm 1.3$ & $1.6 \pm 1.2$ & & $1.6 \pm 1.1$ & $1.6 \pm 1.2$ & \\
\hline Lacticaseibacillus (formerly L. casei subgroup) & $2.7 \pm 1.8$ & $3.7 \pm 1.7$ & & $3.4 \pm 1.9$ & $3.4 \pm 1.9$ & \\
\hline $\begin{array}{l}\text { Limosilactobacillus fermentum (formerly L. } \\
\text { fermentum) }\end{array}$ & $3.0 \pm 1.7$ & $3.2 \pm 1.6$ & & $2.9 \pm 1.6$ & $3.0 \pm 1.5$ & \\
\hline $\begin{array}{l}\text { Fructilactobacillus fructivorans (formerly L. } \\
\text { fructivorans) }\end{array}$ & $1.2 \pm 0.0$ & $1.2 \pm 0.0$ & & $1.2 \pm 0.0$ & $1.2 \pm 0.0$ & \\
\hline $\begin{array}{l}\text { Lactiplantibacillus (formerly L. plantarum } \\
\text { subgroup) }\end{array}$ & $3.4 \pm 1.7$ & $3.4 \pm 1.7$ & & $3.8 \pm 1.3$ & $3.4 \pm 1.7$ & \\
\hline $\begin{array}{l}\text { Limosilactobacillus (except L. fermentum) } \\
\text { (formerly L. reuteri subgroup) }\end{array}$ & $3.4 \pm 1.9$ & $3.2 \pm 1.8$ & $* 0.0415$ & $3.2 \pm 2.0$ & $3.3 \pm 1.9$ & \\
\hline $\begin{array}{l}\text { Ligilactobacillus and Liquorilactobacillus (for- } \\
\text { merly L. ruminis subgroup) }\end{array}$ & $2.5 \pm 2.2$ & $2.3 \pm 2.0$ & & $2.5 \pm 2.1$ & $2.6 \pm 2.1$ & \\
\hline Latilactobacillus (formerly L. sakei subgroup) & $2.4 \pm 1.9$ & $2.4 \pm 1.9$ & & $2.6 \pm 2.0$ & $2.4 \pm 2.0$ & \\
\hline Enterobacteriaceae & $6.5 \pm 0.7$ & $6.4 \pm 0.6$ & & $6.5 \pm 0.7$ & $6.4 \pm 0.6$ & \\
\hline Enterococcus & $5.6 \pm 2.1$ & $5.7 \pm 2.1$ & & $5.9 \pm 1.8$ & $5.7 \pm 2.1$ & \\
\hline Streptococcus & $8.7 \pm 0.6$ & $8.6 \pm 0.6$ & & $8.6 \pm 0.6$ & $8.5 \pm 0.6$ & \\
\hline Staphylococcus & $5.1 \pm 0.9$ & $5.2 \pm 0.7$ & & $4.9 \pm 1.1$ & $5.1 \pm 0.7$ & \\
\hline
\end{tabular}

The results are displayed as the means \pm SD ( $\log 10$ cells/g of feces)

${ }^{*} p<0.05,{ }^{* *} p<0.01$ 
the time required for the insertion of a colonoscope or enema tube.

As mentioned above, this study adopted the YIFSCAN $^{\circledR}$ system for the analysis of fecal bacteria. This system utilizes RT-qPCR targeting bacterial rRNA as an alternative to DNA molecules and enables live gut bacteria to be quantified $[17,18]$. Unlike RT-qPCR targeting RNA and culture counts, qPCR targeting rRNA genes and 4',6-diamidino-2-phenylindole (DAPI) staining counts are relatively constant, even as bacterial cells die. This consistency reflects the fact that qPCR and DAPI staining quantify DNA molecules derived from viable cells as well as those from dead cells; DNA molecules might not degrade rapidly in the dead cells during the late period of culturing $[19,20]$. The YIF-SCAN ${ }^{\circledR}$ system has already been validated for its ability to quantify major human gut bacteria accurately and sensitively [21, 22].

There are several limitations associated with this study. First, the sample size of this study was relatively small. However, significantly higher RCs for the C. coccoides group and $B$. fragilis group, and a tendency toward higher $\mathrm{RC}$ for the C. leptum subgroup, were observed following anaerobic-prep, even with such a small sample size. Overall, anaerobic-prep is considered to be effective in maintaining obligate anaerobes in suspensions intended for use in FMT. Second, this study focused solely on the ratio change in the number of bacteria. We did not assess metabolomic functions, including the microbial capacity for producing butyrate and acetate. Third, our findings demonstrated the need to compare both anaerobic-prep and aerobic-prep in clinical trials to clarify whether these preparation methods have any impact on the effectiveness of FMT for UC patients. In this regard, further investigation is needed.

\section{Conclusion}

In conclusion, anaerobic preparation of fecal slurries contributed to the retention of obligate anaerobes, even in samples maintained under anaerobic conditions for $1 \mathrm{~h}$ post-blending, compared with the conventional aerobic processing. Our findings suggest the importance of anaerobic handling of the donor stool during transportation, mixing, and preservation. These anaerobic preparations might improve the outcome of FMT for UC patients by facilitating the transfer of viable obligate anaerobes.

\section{Methods}

\section{Collection and processing of fecal samples}

We collected fecal samples from each of 16 healthy Japanese volunteers; each volunteer provided informed consent prior to sample collection. Figure 1 shows the stool preparation process. To minimize oxygen exposure during transportation, fecal samples were transferred under anaerobic conditions using an airtight container equipped with a deoxidizer (Anaeropack, SUGIYAMAGEN Co., Ltd., Tokyo, Japan). Fecal samples were placed inside an anaerobic glove box (AS ONE Corporation, Osaka, Japan) within $6 \mathrm{~h}$ of passage. In the glove box, the oxygen concentration was maintained at $<1 \%$ by replacing air with nitrogen using a reverse air pump. As baseline samples, fecal samples were collected and stabilized with RNAlater (Ambion, Austin, TX, USA) before blending $\left(\mathrm{S}_{\text {raw }}\right)$. Fecal samples then were aliquoted into two portions by handling within the glove box. Each aliquot was blended with normal saline water for $30 \mathrm{~s}$, either in the anaerobic glove box (anaerobic-prep) or under room air (aerobic-prep).

As shown in Fig. 1, samples $\mathrm{S}_{\mathrm{An} 0}$ and $\mathrm{S}_{\mathrm{Ae} 0}$ were collected and fixed with RNAlater immediately after blending under anaerobic or aerobic conditions, respectively.

In addition to 0-h samples, we also collected 1-h samples that were stabilized after being maintained for $1 \mathrm{~h}$ under the anaerobic or aerobic conditions. These 1-h samples were designated $S_{A n 1}$ and $S_{A e 1}$, respectively.

To stabilize RNA, each fecal sample $\left(\mathrm{S}_{\mathrm{raw}}, \mathrm{S}_{\mathrm{An} 0}, \mathrm{~S}_{\mathrm{An} 1}\right.$, $\mathrm{S}_{\mathrm{Ae} 0}$, and $\mathrm{S}_{\mathrm{Ael}}$ ) was placed into a tube containing $2 \mathrm{~mL}$ of RNAlater. These samples then were stored at $4{ }^{\circ} \mathrm{C}$ pending analysis of the fecal microbiota.

\section{Analysis of live fecal bacteria}

For the analysis of fecal bacteria, we adopted the YIFSCAN $^{\circledR}$ system, which utilizes RT-qPCR targeting $16 \mathrm{~S}$ and $23 \mathrm{~S}$ rRNA. Using previously described methods [21-25], we extracted total RNA fractions to quantify the bacteria present in the samples. The specificity of the RT-qPCR assay using group-, genus-, or species-specific primers also was determined as described previously [21-25]. Three serial dilutions of the extracted RNA samples were used for bacterial rRNA-targeted RT-qPCR. Threshold cycle values in the linear range of the assay were applied to the standard curve. These data were used to calculate the number of viable bacteria in each sample. For all samples, bacterial PCR products were normalized to the content of a $1-\mathrm{g}$ fecal sample.

\section{Statistical analysis}

All statistical analyses were performed using EZR version 1.38 (Saitama Medical Center, Jichi Medical University, Saitama, Japan), a graphical user interface for $\mathrm{R}$ version 3.5.2 (The R Foundation for Statistical Computing, Vienna, Austria) [26]. Data are expressed as the median and interquartile range for data with skewed distribution. The Wilcoxon signed-rank sum test was used for data analysis, and $P<0.05$ was considered statistically significant. 


\section{Supplementary Information}

The online version contains supplementary material available at https://doi. org/10.1186/s12866-021-02325-9.

\section{Additional file 1.}

\section{Acknowledgments}

We express our sincere gratitude to Yukiko Kado, Akira Takahashi, and Satomi Atobe (Yakult Central Institute) for their valuable assistance in performing the microbiota analyses.

\section{Authors' contributions}

HS, KA, TA, TT, HT, SM, and YY designed the study; HS, IT, and RK acquired data; HS and TA analyzed and interpreted data; $\mathrm{HS}$ drafted the manuscript; $K A$, TA, and $Y Y$ revised the manuscript critically for important intellectual content; All authors reviewed and approved the manuscript.

\section{Funding}

This work was supported, in part, by JSPS KAKENHI (Grant Nos. JP17K18405 and 15 K19647) and by a Grant-in-Aid from the National Center for Child Health and Development from the Ministry of Health, Labour and Welfare of Japan (No. 2017A-3)

\section{Availability of data and materials}

The datasets generated and analyzed during the current study are available in the figshare repository. The raw data of the bacterial counts and $16 \mathrm{~S}$ or $23 \mathrm{~S}$ rRNA gene-targeted primers used in this study have been deposited at figshare repository, with persistent web link: https://doi.org/10.6084/m9.figsh are.14229662

\section{Declarations}

\section{Ethics approval and consent to participate}

The Institutional Review Board of the National Center for Child Health and Development approved this study (No. 1384). Written informed consent was obtained from each subject.

\section{Consent for publication}

Not applicable.

\section{Competing interests}

The authors declare that they have no competing interests.

\section{Author details}

'Division of Gastroenterology, Department of Medical Specialty, National Center for Child Health and Development, Tokyo, Japan. ${ }^{2}$ Department of Pediatrics and Adolescent Medicine, Juntendo University Faculty of Medicine, Tokyo, Japan. ${ }^{3}$ Yakult Central Institute, Tokyo, Japan. ${ }^{4}$ Probiotics Research Laboratory, Juntendo University Graduate School of Medicine, Tokyo, Japan.

Received: 7 July 2021 Accepted: 20 September 2021

Published online: 09 October 2021

\section{References}

1. Zoetendal EG, Rajilic-Stojanovic M, de Vos WM. High-throughput diversity and functionality analysis of the gastrointestinal tract microbiota. Gut. 2008:57(11):1605-15. Epub 2008/10/23. PubMed PMID: 18941009 https://doi.org/10.1136/gut.2007.133603.

2. Shen ZH, Zhu CX, Quan YS, Yang ZY, Wu S, Luo WW, et al. Relationship between intestinal microbiota and ulcerative colitis: Mechanisms and clinical application of probiotics and fecal microbiota transplantation. World J Gastroenterol. 2018;24(1):5-14. doi: https://doi.org/10.3748/wjg. V24.i1.5. Epub 2018/01/24. PubMed PMID: 29358877; PubMed Central PMCID: PMCPMC5757125
3. Guarner F, Malagelada JR. Gut flora in health and disease. Lancet. 2003;361 (9356):512-9. Epub 2003/02/14. PubMed PMID: 12583961. https://doi.org/10.1016/S0140-6736(03)12489-0.

4. Ostling CE, Lindgren SE. Inhibition of enterobacteria and Listeria growth by lactic, acetic and formic acids. J Appl Bacteriol. 1993;75(1):18-24. Epub 1993/07/01. PubMed PMID: 8365950. https://doi.org/10.1111/j.13652672.1993.tb03402.x

5. Furusawa Y, Obata Y, Fukuda S, Endo TA, Nakato G, Takahashi D, et al. Commensal microbe-derived butyrate induces the differentiation of colonic regulatory T cells. Nature. 2013;504(7480):446-50. Epub 2013/11/15. PubMed PMID: 24226770. https://doi.org/10.1038/nature12721.

6. Takaishi H, Matsuki T, Nakazawa A, Takada T, Kado S, Asahara T, et al. Imbalance in intestinal microflora constitution could be involved in the pathogenesis of inflammatory bowel disease. Int J Med Microbiol. 2008;298(5-6):463-72. Epub 2007/09/28. PubMed PMID: 17897884. https://doi.org/10.1016/j.ijmm.2007.07.016.

7. Goyal A, Yeh A, Bush BR, Firek BA, Siebold LM, Rogers MB, et al. Safety, clinical response, and microbiome findings following fecal microbiota transplant in children with inflammatory bowel disease. Inflamm Bowel Dis. 2018;24(2):410-21. Epub 2018/01/24. PubMed PMID: 29361092. https://doi.org/10.1093/ibd/izx035.

8. Bajer L, Kverka M, Kostovcik M, Macinga P, Dvorak J, Stehlikova Z, et al. Distinct gut microbiota profiles in patients with primary sclerosing cholangitis and ulcerative colitis. World journal of gastroenterology. 2017;23(25):4548-58. doi: https://doi.org/10.3748/wjg.v23.i25.4548. Epub 2017/07/26. PubMed PMID: 28740343; PubMed Central PMCID: PMCPMC5504370.

9. van Nood E, Vrieze A, Nieuwdorp M, Fuentes S, Zoetendal EG, de Vos WM, et al. Duodenal infusion of donor feces for recurrent Clostridium difficile. N Engl J Med. 2013;368(5):407-15. Epub 2013/01/18. . PubMed PMID: 23323867. https://doi.org/10.1056/NEJMoa1205037.

10. Moayyedi P, Surette MG, Kim PT, Libertucci J, Wolfe M, Onischi C, et al. Fecal microbiota transplantation induces remission in patients with active ulcerative colitis in a randomized controlled trial. Gastroenterology. 2015;149(1):102-9 e6. Epub 2015/04/11. PubMed PMID: 25857665 https://doi.org/10.1053/j.gastro.2015.04.001.

11. Rossen NG, Fuentes S, van der Spek MJ, Tijssen JG, Hartman JH, Duflou A, et al. Findings from a randomized controlled trial of fecal transplantation for patients with ulcerative colitis. Gastroenterology. 2015;149(1):110-8 e4. Epub 2015/04/04. PubMed PMID: 25836986. https://doi.org/10.1053/j. gastro.2015.03.045.

12. Paramsothy S, Kamm MA, Kaakoush NO, Walsh AJ, van den Bogaerde J, Samuel D, et al. Multidonor intensive faecal microbiota transplantation for active ulcerative colitis: a randomised placebo-controlled trial. Lancet. 2017;389(10075):1218-28. Epub 2017/02/19. PubMed PMID: 28214091. https://doi.org/10.1016/S0140-6736(17)30182-4.

13. Costello SP, Hughes PA, Waters $O$, Bryant RV, Vincent AD, Blatchford $P$, et al. Effect of Fecal Microbiota Transplantation on 8-Week Remission in Patients With Ulcerative Colitis: A Randomized Clinical Trial. Jama. 2019;321 (2):156-64. doi: https://doi.org/10.1001/jama.2018.20046. Epub 2019/01/16. PubMed PMID: 30644982; PubMed Central PMCID: PMCPMC6439766.

14. Tsuji H, Matsuda K, Nomoto K. Counting the Countless: Bacterial Quantification by Targeting rRNA Molecules to Explore the Human Gut Microbiota in Health and Disease. Front Microbiol. 2018;9:1417. doi: https://doi.org/10.3389/fmicb.2018.01417. Epub 2018/07/17. PubMed PMID: 30008707: PubMed Central PMCID: PMCPMC6033970.

15. Ding X, Li Q, Li P, Zhang T, Cui B, Ji G, et al. Long-term safety and efficacy of fecal microbiota transplant in active ulcerative colitis. Drug Saf 2019;42(7):869-880. Epub 2019/04/12. doi: https://doi.org/10.1007/ s40264-019-00809-2. PubMed PMID: 30972640.

16. Papanicolas LE, Choo JM, Wang Y, Leong LEX, Costello SP, Gordon DL, et al. Bacterial viability in faecal transplants: Which bacteria survive? EBioMedicine. 2019:41:509-16. doi: https://doi.org/10.1016/j.ebiom.2019.02. 023. Epub 2019/02/24. PubMed PMID: 30796005; PubMed Central PMCID: PMCPMC6444077.

17. Bleve G, Rizzotti L, Dellaglio F, Torriani S. Development of reverse transcription (RT)-PCR and real-time RT-PCR assays for rapid detection and quantification of viable yeasts and molds contaminating yogurts and pasteurized food products. Appl Environ Microbiol. 2003;69(7):4116-22. 
doi: https://doi.org/10.1128/aem.69.7.4116-4122.2003. Epub 2003/07/04. PubMed PMID: 12839789; PubMed Central PMCID: PMCPMC165170.

18. McKillip JL, Jaykus LA, Drake M. rRNA stability in heat-killed and UV-irradiated enterotoxigenic Staphylococcus aureus and Escherichia coli 0157:H7. Appl Environ Microbiol. 1998;64(11):4264-8. doi: https://doi.org/10.1128/ AEM.64.11.4264-4268.1998. Epub 1998/10/31. PubMed PMID: 9797275; PubMed Central PMCID: PMCPMC106637.

19. Josephson KL, Gerba CP, Pepper IL. Polymerase chain reaction detection of nonviable bacterial pathogens. Appl Environ Microbiol. 1993;59(10):3513-5. doi: https://doi.org/10.1128/AEM.59.10.3513-3515. 1993. Epub 1993/10/01.PubMed PMID: 8250575; PubMed Central PMCID: PMCPMC182487.

20. Kurakawa T, Kubota H, Tsuji H, Matsuda K, Asahara T, Takahashi T, et al. Development of a sensitive rRNA-targeted reverse transcription-quantitative polymerase chain reaction for detection of vibrio cholerae/mimicus, V. parahaemolyticus/alginolyticus and campylobacter jejuni/coli. Microbiol Immunol. 2012;56(1):10-20. Epub 2011/12/08. PubMed PMID: 22146006. https://doi.org/10.1111/j.1348-0421.2011.00405.x.

21. Matsuda K, Tsuji H, Asahara T, Kado Y, Nomoto K. Sensitive quantitative detection of commensal bacteria by rRNA-targeted reverse transcriptionPCR. Appl Environ Microbiol. 2007;73(1):32-9. doi: https://doi.org/10. 1128/AEM.01224-06. Epub 2006/10/31. PubMed PMID: 17071791; PubMed Central PMCID: PMCPMC1797142.

22. Matsuda K, Tsuji H, Asahara T, Matsumoto K, Takada T, Nomoto K. Establishment of an analytical system for the human fecal microbiota, based on reverse transcription-quantitative PCR targeting of multicopy rRNA molecules. Appl Environ Microbiol. 2009;75(7):1961-9. doi: https://doi.
org/10.1128/AEM.01843-08. Epub 2009/02/10. PubMed PMID: 19201979; PubMed Central PMCID: PMCPMC2663197

23. Sakaguchi S, Saito M, Tsuji H, Asahara T, Takata O, Fujimura J, et al. Bacterial rRNA-targeted reverse transcription-PCR used to identify pathogens responsible for fever with neutropenia. J Clin Microbiol. 2010;48(5):16248. doi: https://doi.org/10.1128/JCM.01724-09. Epub 2010/03/31. PubMed PMID: 20351213; PubMed Central PMCID: PMCPMC2863901.

24. Ohigashi S, Sudo K, Kobayashi D, Takahashi O, Takahashi T, Asahara T, et al. Changes of the intestinal microbiota, short chain fatty acids, and fecal pH in patients with colorectal cancer. Dig Dis Sci. 2013;58(6):1717-26. Epub 2013/01/12. PubMed PMID: 23306850. https://doi.org/10.1007/ s10620-012-2526-4.

25. Hojo M, Asahara T, Nagahara A, Takeda T, Matsumoto K, Ueyama H, et al. Gut Microbiota Composition Before and After Use of Proton Pump Inhibitors. Dig Dis Sci. 2018;63(11):2940-9. doi: https://doi.org/10.1007/s 10620018-5122-4. Epub 2018/05/26. PubMed PMID: 29796911; PubMed Central PMCID: PMCPMC6182435.

26. Kanda Y. Investigation of the freely available easy-to-use software 'EZR' for medical statistics. Bone Marrow Transplant. 2013;48(3):452-8. Epub 2012/12/05. doi: https://doi.org/10.1038/bmt.2012.244. PubMed PMID: 23208313; PubMed Central PMCID: PMCPMC3590441.

\section{Publisher's Note}

Springer Nature remains neutral with regard to jurisdictional claims in published maps and institutional affiliations.
Ready to submit your research? Choose BMC and benefit from:

- fast, convenient online submission

- thorough peer review by experienced researchers in your field

- rapid publication on acceptance

- support for research data, including large and complex data types

- gold Open Access which fosters wider collaboration and increased citations

- maximum visibility for your research: over $100 \mathrm{M}$ website views per year

At BMC, research is always in progress.

Learn more biomedcentral.com/submissions 